\title{
Managing the Coexistence of Hierarchical and Collegial Governance Structures
}

\author{
Nancy A. Brown
}

Dual structures of governance, that is, the collegial and the hierarchical, are in place in many university libraries today. The problems from a managerial perspective of managing the coexistence of these governance structures may include accountability, lack of organizational flexibility, time requirements, communication between the structures, some lessening of librarians' interest in the function of line management, the potential for goal conflict, and a lack of appreciation for librarians' position in their bargaining group. While there is no one solution to these problems, it is imperative that university libraries operate in such a manner as to be judged effective or the mandate of the library stands in some danger of being at least partially distributed.

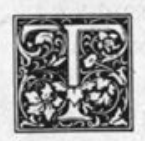

he need to recognize and to manage the coexistence of hierarchical and collegial governance structures in academic libraries is a phenomenon of the last fifteen years. During this period, faculty members, including librarians, have commonly formed associations or unions to bargain for terms and conditions of work. It should be acknowledged without reservation that where these associations or unions are legally recognized to bargain by provincial or state or federal jurisdictions, they have all attendant rights and responsibilities including the duty of fair representation. Faculty associations or unions are distinct, however, from other unions because the traditional collegial processes form an integral part of the agreements and these processes are enforceable by law under labor relations boards.

Librarians have sought and frequently achieved comparability with faculty with respect to collegial processes and peer review. But libraries, unlike academic colleges and departments, have more formal hierarchical structures. These hierarchies can be illustrated by the organization chart of any university library. Anything fewer than four organizational levels is unusual. A collegial structure somehow linked or paralleled with a hierarchical structure, that is, two governance structures, results in a complex formal organizational structure. Where authority and responsibility diverge significantly the structure may be unstable. The outcome for the library may be an ineffectual response to a university environment which itself may be in a state of retrenchment, rapid change and technological innovation.

Library governance must be equal to the demands placed upon it because the library is essential to the teaching and re-

Nancy A. Brown is university librarian and director of libraries at the University of Saskatchewan, Saskatoon, Canada S7N OWO. This paper was presented at an invitational conference, "Administrative Perspectives on the Changing Role of Libraries in Higher Education: Critical Issues and Challenges for the 80s, " held at Northern Illinois University, DeKalb, Illinois, September 17-18, 1984. The author is grateful to her colleagues for helpful discussions, and would particularly like to thank Frank Winter, associate university librarian, University of Saskatchewan. 
search function of the university. Research libraries are among the major cost centers on campus. Given the need and the cost, libraries will be asked by users and by university officials to operate effectively. Otherwise, their functions may be at least partially distributed. This would be exceedingly unfortunate because libraries that are well positioned with respect to computer and communication technologies, that have strong political profiles in the universities, and that have experienced managers and expert systems staff could make a significant contribution to the information and technological revolution that is underway on the campuses.

\section{DIMENSIONS OF COLLEGIAL INFLUENCE OR CONTROL}

In academic libraries collegial models have three dimensions of influence or control. ${ }^{1}$ These are:

1. The degree of control. This may refer to the amount of influence a collegial committee has on any decision. The amount of influence, or the degree of control, depends on whether the recommendations of the committee are advisory or are binding by virtue of tradition or agreement. For example, a committee of peers exercises control when it decides who will receive merit increases.

2. The issues subject to control. Here, for example, search, promotion and tenure committees, with the majority of members elected, may determine who will join the staff, who will be promoted, who will be rewarded, and who will receive tenure.

3. The level at which control is exercised. A collegial governance structure in coexistence with a hierarchy can exercise control or influence at any level from individual library department to the senior university administration.

In unionized organizations, representatives of the collegial processes as well as individuals can expect to influence their union. In turn, the union has legitimate power in dealing with senior university administration.

These three dimensions, the degree, the issues, and the level at which control or influence are exercised can range from per- functory through advisory to full decision-making power. In a unionized university all three dimensions are matters for negotiation.

\section{STRUCTURE}

The structure of an organization is the vehicle by which choices are made on how the work of the organization will be divided and how coordination and integration are effected. The structure of a hierarchy is well known; traditionally, in a library the division of work has been between public service, technical service, and perhaps systems, with coordination achieved through line and staff positions and through standing management committees. This traditional structure is changing in response to technological developments. Other formal structures are replacing it. For example, a matrix structure is sometimes employed during extended or ongoing development or implementation projects.

In considering the organizational structure of a library, it is important to remember the composition of the staff. In Canada, the ratio of support staff to librarians is about three to one. The number of nonlibrarian professionals or specialists is small but is believed to be growing. Since non-librarian professional and support staff members ( 70 to 80 percent of the total staff) are excluded from the collegial process, a research library cannot operate with only a collegial structure in place. There must be a hierarchical or matrix structure for the library to achieve the goals for which it exists.

\section{CONCERNS FROM A MANAGERIAL PERSPECTIVE}

Given the continued coexistence of hierarchical and collegial structures, what are the problems of management?

The most serious problem may well be accountability. The chief librarian is held accountable by the university administration and the faculty at large for the efficiency and effectiveness with which the library meets its mandate. Collegial committees come together, make decisions, and disperse. The decisions are typically related to functions such as hiring, 
promotion, tenure, and assignment of duties. Collegial committees may or may not have direct policy making power, but decisions on hiring, promotion, tenure, and assignment of duties will clearly affect policy making and policy implementation. With respect to accountability, individual committee members may or may not personally accept responsibility for decisions. Even if individuals do accept responsibility, their options to demonstrate accountability are limited. There may be the power to make decisions without responsibility for the outcome.

Accountability follows the hierarchical structure. The collegium with advisory or decision-making power answers to itself. The views of the collegium may coincide as frequently with the views of library administration as the views of the teaching faculty coincide with the views of the university administration.

Another problem may well be a lack of organizational flexibility. It may be difficult to reorganize to respond to the changing environment, particularly with respect to technology, retrenchment, and user needs. In unionized organizations, it may be virtually impossible to shift the positions between bargaining groups.

A third problem is that the management of a collegial structure demands large amounts of time for committee deliberations and agreement administration. The governance of the librarian collegium can be very costly.

The fourth concern relates to communication between the structures. The transfer of information, particularly personnel information, between the hierarchical and collegial structures is a matter deserving respect. Documentation may or may not flow from the hierarchy to collegial committees; normally it does not flow from collegial committees back to the hierarchy. This may limit a department head in efforts to counsel and develop a staff member.

A fifth problem is that there is some evidence to suggest a growing ambiguity in the commitment of research librarians to the function of management. Librarians are advancing very strong arguments for the implementation of career ladders for librarians without managerial responsibilities that would enable such librarians, in a normal career progression, to reach a salary and position level equivalent to full professor. Librarians have, for many reasons, sought to increase their community of interest with teaching and research faculty members. Line and staff management are generally not part of a faculty member's professional responsibilities and this may account for some ambiguity. Some librarians consider nonmanagerial positions intellectually superior.

If there is widespread ambiguity with respect to the function of management, and if collegial committees allocate rewards such as merit increases, then librarian managers may not be rewarded for their management skills. This, may lead to a nonmanagement orientation. It may encourage the best librarian managers to seek other employment, and it can divide the librarian collegium.

If librarians increasingly choose alternate career routes and nonmanagerial senior positions, then who will manage the library? Whether or not librarians wish to manage, many of them find it completely and unalterably unacceptable to take direction from nonlibrarian professionals or support staff. In my judgement, librarians cannot adopt the view of some faculty that they will neither manage nor be managed. Overall, if a significant number of the best and brightest librarians do not accept managerial duties, then the strain and friction in the library will increase substantially.

A sixth problem is the potential for department heads and other senior librarians with management responsibilities who are members of legally recognized faculty associations or unions to experience goal conflict. These individuals may be required to take a position on such issues as job action, withdrawal of certain services or budget cuts involving collegium members. Simultaneously, these individuals have line management responsibilities that include advising the chief librarian on a course of action designed for the greater good of the library. This is typically a retrenchment problem.

The difficulties of managing can be con- 
siderably exacerbated by senior university officials who, for whatever reason, do not understand or appreciate the position of librarians with respect to status, affiliation, and bargaining group.

Libraries, like other organizations, can be assessed by four criteria: by how they meet their goals, by the resources they attract, by the absence of internal strain, and by the degree to which all constituents are minimally satisfied. The problems inherent in managing the coexistence of the collegial structure and hierarchical structure can potentially lead to negative assessments on all four criteria. This may occur in association, union, and nonunion organizations, because the collegial structure has to have power and legitimacy to enforce its rights as it sees them, or it is not a viable governance structure.

While there is no simple resolution of the aforementioned concerns, it should be clearly understood that the two structures will continue to coexist. Good management practices are essential if the system is to work. One might hypothesize that the development of a climate of excellence and a culture of innovation and progress are to be desired. If the situation becomes totally unworkable, the only structural response is to redesign the delivery of library service.

\section{COLLECTIVE AGREEMENTS OR FORMAL TERMS AND CONDITIONS OF EMPLOYMENT DOCUMENTS FROM A MANAGERIAL PERSPECTIVE}

With respect to collective agreements or formal terms and conditions of employment documents and dual structures, the following points bear some consideration:

1. The negotiators should clearly understand the particular circumstances of the university library, including (a) the importance of the library to the academic process and a recognition of the fact that although the number of librarians is small compared to the number of faculty, librarians are essential to the operation of the library; (b) the need for flexibility to respond to technological developments and changing user needs; (c) the need for flexi- bility to respond to retrenchment; for example, libraries cannot take all major personnel reductions from the support staff establishment and still operate; and (d) a hierarchical structure is in place because it is the only way to divide and coordinate the work of several hundred people and to provide some accountability.

2 . It is only prudent to seek the best possible advice when first agreements are being negotiated.

3. Communication between library directors and chief management negotiators should be full and open.

4. There should be a senior library administrator on management negotiating teams.

5. Senior university officials should be readily available during the term of the agreement to provide quick, authoritative, consistent management interpretations as they are required and where there are campuswide implications.

6. Assignment of duties should be appropriate to bargaining groups.

7. Management rights should not be given away unilaterally by poor management practices.

8. Finally, all parties should accept terms and conditions of employment documents or collective agreement documents when they are in place, and further, respect them. It is only after accepting the legitimacy of the existence of the two structures that the organization will function as it should.

\section{IMPACT OF TECHNOLOGY}

Technology has only been mentioned briefly, but it is the driving force of the decade. It is changing the world, and the question of whether libraries can move with the online environment of the information age and retain their relative position of importance in universities is, in my judgement, still open. Over the next ten years, technological development will both permit and dictate fundamental changes in information handling. As Russell Shank pointed out, "Because more people and groups on campuses, other than librarians, now have strong vested interests in the installation, management, and use of information handling facilities, 
the process of dealing with the issues is much more sophisticated, difficult, and time consuming than it ever has been." Unless a library goes into this environment with an overriding commitment, supported by demonstrated local library systems expertise, to use technology to achieve excellence in information access, collections, and services, the chances of the library remaining a major constituent of the information-handling campus consortium are reduced. The costs of technology and the need to integrate computing, communications, and all other information resources on campus will forge new university organization structures. ${ }^{3}$ The place of the library, as it now generally constituted, is not guaranteed in that new structure.

\section{REFERENCES}

1. Nancy Brown, "Academic Libraries, an Operational Model for Participation," Canadian Library Journal 36:201-7 (August 1979).

2. Russell Shank, "Academic Institutions and the Advent of the Information Age," Association of Research Libraries, minutes of the 102nd Meeting, Banff, Canada May 4-6, 1983. p.25.

3. Nancy A. Brown, "Administration in the Online Environment," Association of Research Libraries, minutes of the 102nd Meeting, Banff, Canada May 4-6, 1983. p.32.

\section{IN FORTHCOMING ISSUES OF COLLEGE \& RESEARCH LIBRARIES}

The Client-Librarian Relationship in Reference

by Joan C. Durrance

Involvement of Academic Librarians in Curriculum Change

by Catherine Pasterczyk

Academic Library Regional Accreditation

by Mary F. Casserly

Knowledge Bases and Library Education

by Ronald R. Powell and Sheila D. Creth

Copyright and Fee-Based Library Copying Services

by James S. Heller

The Reliability Factor in Subject Access

by Constance McCarthy

Selected Reference Books

by Eugene P. Sheehy 